sun. Those are, of course, conclusions which a very restricted study of physical science will make perfectly clear: why you get the two reds together when two bows are visible; why the blue is inside, and the red outside the single bow, also follows from a demonstration which your teacher will give you, or which you can get from a book. The main point is that a rainbow is produced by a physical cause ; so that, if you once grasp the idea of the cause of a rainbow, its whole anatomy will remain for ever with you.

It is quite impossible for you to see a rainbow in prospective, or projected on the sky as an ellipse. That will be quite clear, I think. Still, both these are recognized art-objects. I am sorry to say that in this year's Acaderny there is one case in which you will find that the fundamental condition of having your back to the sun has been neglected or forgotten by the artist. In No. 395 a most exquisite stump of rainbow is seen most beautifully painted, and you naturally think, of course, that you have your back to the sun, but the artist has not been contented with painting the rainbow, he has painted cattle as well, and their shadows sweep across the picture. Another rainbow, 595, is excellently painted. The artist not only knows a great deal about rainbows, but wishes you to know that he knows, an umbrella being emphatically en évidence.

(To be continued.)

\section{THE FARADAY CENTENARY.}

$\mathrm{O}$

$\mathrm{N}$ Wednesday, June $\mathrm{I} 7$, at the Royal Institution, Lord Rayleigh delivered a lecture in connection with the hundredth anniversary of Faraday's birth. The Prince of Wales presided.

Lord Rayleigh said that the man whose name and work they were celebrating was identified in a remarkable degree with the history of that Institution. If they could not take credit for his birth, in other respects they could hardly claim too much. During a connection of fifty-four years, Faraday found there his opportunity, and for a large part of the time his home. The simple story of his life must be innown to most who heard him. Fired by contact with the genius of Davy, he volunteered his services in the laboratory of the Institution. Davy, struck with the enthusiasm of the youth, gave him the desired opportunity, and, as had been said, secured in Faraday not the least of his discoveries. The early promise was indeed amply fulfilled, and for a long period of years by his discoveries in chemistry and electricity Faraday maintained the renown of the Royal Imstitution and the honour of England in the eye of the civilized world. He should not attempt in the time at his disposal to trace in any detail the steps of that wonderful career. The task had already been performed by able hands. In their own Proceedings they had a vivid sketch from the pen of one whose absence that day was a matter of lively regret. Dr. Tyndall was a personal friend, had seen Faraday at work, had enjoyed opportunities of watching the action of his mind in face of a new idea. All that he could aim at was to recall, in a fragmentary manner, some of Faraday's great achievements, and if possible to estimate the position they held in contemporary science.

Whether they had regard to fundamental scientific import, or to practical results, the first place must undoubtedly be assigned to the great discovery of the induction of electrical currents. $\mathrm{He}$ proposed first to show the experiment in something like its original form, and then to pass on to some variations, with illustrations from the behaviour of a model, whose mechanical properties were analogous. He was afraid that these elementary experiments would tax the patience of many who heard him, but it was one of the difficulties of his task that Faraday's discoveries were so fundamental as to have become familiar to all serious students of physics.

The first experinent required them to establish in one coil of copper wire an electric current by completing the communication with a suitable battery; that was called the primary circuit, and Faraday's discovery was this: That at the moment of the starting or stopping of the primary current, then, in a neighbouring circuit, in the ordinary sense of the words, completely detached, there was a tendency to induce a current. He had said that those two circuits were perfectly distinct, and they were distinct in the sense that there was no conducting communication between them, but, of course, the importance of the experiment resided in this-that it proved that in some sense the circuits were not distinct; that an electric current circulating in one does produce an effect in the other, which is propagated across a perfectly blank space occupied by air, and which might equally well have been occupied by vacuum. It might appear that that was a very simple and easy experiment, and of course it was so in a modern laboratory, but it was otherwise at the time when Faraday first made it. With all his skill, Faraday did not light upon truth without delay and difficulty. One of Faraday's biographers thus wrote:-- In December I 824 , he had attempted to obtain an electric current by means of a magnet, and on three occasions he had made elaborate and unsuccessful attempts to produce a current in one wire by means of a current in another wire, or by a magnet. He still persevered, and on August 29, 1831-that is to say, nearly seven years after his first attempts-he obtained the first evidence that an electric current induced another in a different circuit. On September $23 \mathrm{rd}$, he writes to a friend, R. Phillips: I am busy just now again with electro-magnetism, and think I have got hold of a g ood thing, but cannot say; it may be a weed instead of a fish that, after all my labour, I at last haul up." We now know that it was a very big fish indeed. Lord Rayleigh proceeded to say that he now proposed to illustrate the mechanics of

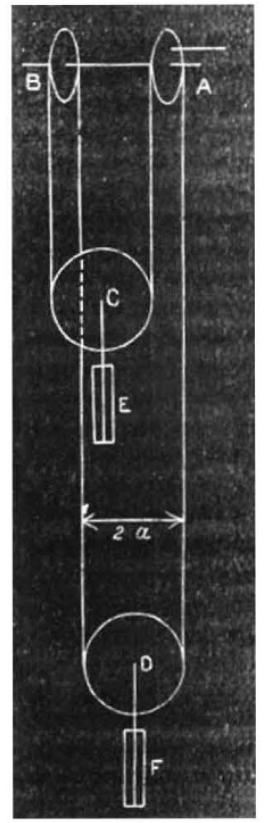

the question of the induced current by means of a model (see figure), the first idea of which was due to Maxwell. The one actually employed was a combination known as Huygens's gear, invented by him in connection with the winding of clocks. Two similar pulleys, A, B, turn upon a piece of round steel fixed horizontally. Over these is

NO. I I 3 O, VOL. 44] 
hung an endless chord, and the two bights carry similar pendant pulleys, C, D, from which again hang weights, E, F. The weight of the cord being negligible, the system is devoid of potential energy ; that is, it will balance, whatever may be the vertical distance between $C$ and $D$. Since either pulley, A, B, may turn independently of the other, the system is capable of two independent motions. If $A, B$ turn in the same direction and with the same velocity one of the pendant pulleys, C, D, rises, and the other falls. If, on the other hand, the motions of $A, B$ are equal and opposite, the axes of the pendant pulleys and the attached weights remain at rest. In the electrical analogue the rotatory velocity of A corresponds to a current in a primary circuit, that of $\mathrm{B}$ to a current in a secondary. If, when all is at rest, the rotation of $\mathrm{A}$ be suddenly started, by force applied at the handle or otherwise, the inertia of the masses $\mathrm{E}$, $\mathrm{F}$ opposes their sudden movement, and the consequence is that the pulley B turns backwards, $i . e$. in the opposite direction to the rotation imposed upon A. This is the current induced in a secondary circuit when an electromotive force begins to act in the primary. In like manner, if $\mathrm{A}$, having been for some time in uniform movement, suddenly stops, B enters into motion in the direction of the former movement of $\mathrm{A}$. This is the secondary current on the break of the current in the primary circuit. It might perhaps be supposed by some that the model was a kind of trick. Nothing could be further from the truth. The analogy of the two things was absolutely essential. So far was this the case that precisely the same argument and precisely the same mathematical equations proved that the model and the electric currents behaved in the way in which they had seen them behave in the experiment. That might be considered to be a considerable triumph of the modern dynamical method of including under the same head phenomena the details of which might be so different as in this case. If they had a current which alternately stopped and started, and so on, for any length of time, they, as it were, produced in a permanent manner some of the phenomena of electrical induction. The particular apparatus by which he proposed to illustrate those effects of the alternating current was devised by a skilful American electrician, Prof. Elihu Thomson, and he had no doubt it would be new to many. The alternating current was led into the electro-magnet by a suitable lead; if another electric circuit, to be called the secondary circuit, was held in the neighbourhood of the first, currents would be induced and might be made manifest by suitable means. Such a secondary circuit he held in his hand, and it was connected with a small electric glow lamp. If a current of sufficient intensity were induced in that secondary circuit it would pass through the lamp, which would be rendered incandescent. [Illustrating.] It was perfectly clear there was no conjuring there; the incandescent lamp brightened up. One of the first questions which presented itself was, what would be the effect of putting something between? Experimenting with a glass plate, he showed there was no effect, but when they tried a copper plate the lamp went completely out, showing that the copper plate was an abjolute screen to the effect, whatever it might be. Experiments of that kind, of course in a much less developed and striking form, were made by Faraday himself, and must be reckoned amongst some of his greatest discoveries.

Before going further, he mi sht remark on what strong evidence they got in that way of the fact that the propagation of the electric energy which, having its source in the dynamo downstairs, eventually illuminated that little lamp, was not merely along the wires, but was capable of bridging over and passing across a space free from all conducting material, and which might be air, glass, or, equally well, vacuum. Another kindred effect of a striking nature, devised by Prof. Elihu Thomson, consisted in the repulsive action which occurred between the primary current circulating around a magnet and the current induced in a single hoop of aluminium wire. Illustrating this by experiment, he showed that the repulsion was so strong as to throw the hoop up a considerable height. Those effects were commonly described as dependent upon the mutual induction between two distinct circuits, one being that primarily excited by a battery or other source of electricity, while the other occurred in a detached circuit. Many surprising effects, however, depended on the reactions which took place at different parts of the same circuit. One of these he illustrated by the decomposition of water under the influence of a single Daniell cell with the aid of self-induction.

About the time that the experiments of which he had been speaking were made, Faraday evidently felt un easiness as to the soundness of the views about electricity held by his contemporaries, and to some extent shared by himself, and he made elaborate experiments to remove all doubt from his mind. He re-proved the complete identity of the electricity of lightning and of the electricity of the voltaic cell. He was evidently in terror of being misled by words which might convey a meaning beyond that which facts justified. Much use was made of the term "poles" of the galvanic battery. Faraday was afraid of the meaning which might be attached to the word "pole," and he introduced a word since generally substituted, "electrode," which meant nothing more than the way or path by which the electricity was led in. "Electric fluid" was a term which Faraday considered dangerous, as meaning more than they really knew about the nature of electricity, and as was remarked by Maxwell, Faraday succeeded in banishing the term "electric fluid " to the region of newspaper paragraphs

Diamagnetism was a subject upon which Faraday worked, but it would take him too long to go into that subject, though he must say a word or two. Faraday found that whereas a ball of iron or nickel or cobalt, when placed near a magnet or combination of magnets, would be attracted to the place where the magnetic force was the greatest, the contrary occurred if for the iron was substituted a corresponding mass of bismuth or of many other substances. The experiments in diamagnetism were of a microscopic character, but he would like to illustrate one position of Faraday's, developed years afterwards by Sir Wm. Thomson, and demonstrated by him in many beautiful experiments, only one of which he now propused to bring before them. Supposing they had two magnetic poles, a north pole and a south pole, with an iton ball between them, free to move along a horizontal line perpendicular to that joining the poles, then, according to the rule he had stated, the iron ball would seek an intermediate position, the place at which the magnetic force was the greatest. Consequently, if the iron ball be given such a position, they would find it tended with considerable force to a central position of equilibrium ; but if, instead of using opposite poles, they used, e.g., two north poles, they would find that the iron ball did not tend to the central position, because that was not the position in which the magnetic force was the greatest. At that position there was no magnetic force, for the one pole completely neutralized the action of the other. The greatest force would be a little way out, and that, according to Faraday's observations, systematized and expressed in the form of mathematical law by Sir Wm. Thomson, was where the ball would go. [This was illustrated by experiment.]

The next discovery of Faraday to which he proposed to call attention was one of immense significance from a scientific point of view, the consequences of which were not even yet fully understood or developed. He referred to the magnetization of a ray of light, or what was called

NO. I I 3 O, VOL. 44] 
in more usual parlance the rotation of the plane of polarization under the action of magnetic force. [t would be hopeless to attempt to explain all the preliminaries of the experiment to those who had not given some attention to those subjects before, and he could only a tempt it in general teims. It would be known to most of them that the vibrations which constituted light were extcuted in a direction perpendicular to that of the ray of light. By experiment he showed that the polarization which was suitable to pass the first obstacle was not suitable to pass the second, but if by means of any mechanism they were able, after the light had passed the first obstacle, to turn round the vibration, they would then give it an opportunity of passing the second obstacle. That was what was involved in Faraday's discovery. [Experiment.] As he had said, the full significance of the experiment was not yet realized. A large step towards realizing it, however, was contained in the observation of Sir William Thomson, that the rotation of the plane of polarization proved that something in the nature of rotation must be going on within the medium when subjected to the magnetizing force, but the precise nature of the rotation was a matter for further speculation, and perbaps might not be known for some time to come.

When first considering what to bring before them he thought, perhaps, he might include some of Faraday's acoustical experiments, which were of great interest, though they did not attract so much attention as his fundamental electrical discoveries. He would only allude to one point which, as far as he knew, had never been noticed, but which Faraday recorded in his acoustical papers. "If during a strong steady wind, a smooth flat sandy shore, with enough water on it, either from the receding tide or from the shingle above, to cover it thoroughly, but not to form waves, be observed in a place where the wind is not broken by pits or stones, stationary undulations will be seen over the whole of the wet surface. These are not waves of the ordinary kind, they are (and this is the remarkable point) accurately parallel to the course of the wind." When he first read that statement, many years ago, he was a little doubtful as to whether to accept the apparent meaning of Faraday's words. He knew of no suggestion of an explanation of the possibility of waves of that kind being generated under the action of the wind, and it was, therefore, with some curiosity that two or three years ago, at a French watering-place, he went out at low tide, on a suitable day when there was a good breeze blowing, to see if he could observe anything of the waves described by Faraday. For some time he failed absolutely to observe the phenomenon, but after a while he was perfectly well able to recognize it. He mentioned that as an example of Faraday's extraordinary powers of observation, and even now he doubted whether anybody but himself and Faraday had ever seen that phenomenon.

Many matters of minor theoretic interest were dealt with by Faraday, and reprinted by him in his collected works. He was reminded of one the other day by a lamentable accident which occurred owing to the breaking of a paraffin lamp. Faraday called attention to the fact, though he did not suppose he was the first to notice it, that, by a preliminary preparation of the lungs by a number of deep inspirations and expirations, it was possible so to aerrate the blood as to allow of holding the breath for a much longer period than without such a preparation would be possible. He remembered some years ago trying the experiment, and running up from the drawingroom to the nursery of a large house without drawing any breath. That was obviously of great practical importance, as Faraday pointed out, in the case of danger from suffocation by fire, and he thought that possibly the accident to which he alluded might have been spared had the knowledge of the fact to which Faraday drew attention been more generally diffused.
The question had often been discussed as to what would have been the effect upon Faraday's career of discovery had he been subjected in early life to mathematical training. The first thing that occurred to him about that, after reading Faraday's works, was that one would not wish him to be anything different from what he was. If the question must be discussed, he supposed they would have to admit that he would have been saved much wasted labour, and would bave been better en rapport with his scientific contemporarit $s$ if he had had elementary mathematical instruction. But mathematical training and mathematical capacity were two different things, and it did not at all follow that Faraday had not a mathematical mind. Indeed, some of the highest authorities (and there could be no higher authority on the subject than Maxwell) had held that his mind was essentially mathematical in its qualities, although they must admit it was not developed in a mathematical direction. With these words of Maxwell he would conclude: "The way in which Faraday made use of his idea of lines of force in coordinating the phenomena of electric induction shows him to have been a mathematician of high order, and one from whom the mathematicians of the future may derive valuable and fertile methods."

\section{THE ROYAL NAVAL EXHIBITION.}

THE Naval Exhibition, now being held at Chelsea, is distinctly a popular show. The management-recognizing that the first duty of an Exhibition is not to show a pecuniary deficit--has wisely decided to follow the lead given by Sir Philip Cunliffe Owen, and has devoted the chief of its energies to fireworks, waxworks, peep-shows, pictures, shooting-galleries, mimic sham fights, and musical entertainments of a kind known to sailors as "sing-songs." The end justifies the means. Not only does the Committee of distinguished Admirals labour to supply Londoners with a cheap and innocent means of enjoyment, but the final result wlll be the establishment of a substantial fund to endow a most deserving charity. Fortuitously there are features which possess a more serious interest; and though there may be nothing especially new in the Exhibition, the man of science who has not been brought much in contact with naval matters may find there a good deal that is worth consideration.

The Exhibition appears to be divided into about half-adozen sections, each under the direction of a committee. Of these the "Entertainments" and "Refreshments" Committees are of course the chief; but the Models Committee appears to be the one which has made the most serious effort to present a distinctly naval subject in logical sequence. In the Seppings Gallery there is a collection of models of warships illustrating the progress of naval architecture, from the Great Harry down to the very latest design of armour-clad battleship. The model of the Great Harry is of very doubtful authenticity, and is of modern construction, having been made by the aid of such pictures of the great sixteenth-century ship as exist. No historical collection of British warships would, however, be even approximately complete without a representation of this vessel. Charnock, our great authority on the subject, has styled her "the parent of the British Navy"; and if it be true, as supposed, that she was the first warship to sail on a wind, the claim is most amply justified In fact, naval architecture as a science was not founded until it was discovered that ships could be, otherwise than by the aid of oars, taken to the quarter from which the wind was blowing. It must have seemed a great feat in those days-little less than necromancy. Fortunately for the timid intellects of our ancestors, the revelation broke upon them gently, for the rounded hulls, high topsides, and curiously rigged craft could not have sailed more than a point or two to wind-

$$
\text { No. I I } 30 \text {, VOL. 44] }
$$

